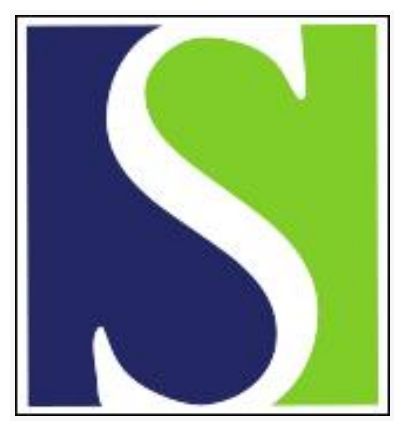

Scand J Work Environ Health 2004;30(1):47-55

https://doi.org/10.5271/sjweh.764

Issue date: Feb 2004

Psychosocial job factors and the one-year evolution of back-related functional limitations

by Leroux I, Dionne CE, Bourbonnais $R$

Affiliation: Unité de recherche en santé des populations, Centre de recherche du CHA de Québec Hôpital du St-Sacrement, 1050 chemin Ste-Foy, Québec (GUE) Canada, G1S4L8. isabelle.leroux@uresp.ulaval.ca

Refers to the following texts of the Journal: 1995;21(6):435-439 1995;21(2):134-142 2001;27(4):258-267

The following article refers to this text: $2008 ; 34(6): 438-443$

Key terms: back; back pain; decision latitude; disability; functional limitation; job factor; psychological demand; psychosocial factor; psychosocial job factor; psychosocial work environment; social support

This article in PubMed: www.ncbi.nlm.nih.gov/pubmed/15018028

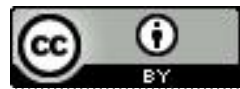




\title{
Psychosocial job factors and the one-year evolution of back-related functional limitations
}

\author{
by Isabelle Leroux, MSc, ${ }^{1}$ Clermont E Dionne, PhD, ${ }^{1,2}$ Renée Bourbonnais, DSc ${ }^{2,3}$
}

Leroux I, Dionne CE, Bourbonnais R. Psychosocial job factors and the one-year evolution of back-related functional limitations. Scand J Work Environ Health 2004;30(1):47-55.

\begin{abstract}
Objectives This 1-year prospective study aimed at assessing the association between some psychosocial job characteristics and back-related functional limitations.

Methods The participants were 849 workers who sought medical consultation for nonspecific back pain in primary care settings of the Quebec City area. Information on job decision latitude, psychological demands, and social support at work was collected during a telephone interview conducted after the medical consultation. Back-related functional limitations were measured at baseline and 1 year later with the Roland-Morris Disability Questionnaire. The analyses were stratified by gender. Social support at work and the type of back pain were considered potential effect modifiers. Several potential confounders were also considered in the multiple regression analyses that were conducted to isolate the effect of the job psychological demands and decision latitude on the 1-year level of back-related functional limitations.

Results A modest difference in the 1-year Roland-Morris average scores was found only among the women and only for the association between job decision latitude with back-related functional limitations, according to the level of social support at work. This difference was of limited clinical significance. Analyses by type of back pain showed, however, a clinically significant association between the combination of high psychological demands and low decision latitude and back-related functional limitations only for subjects with persistent pain.

Conclusions Job psychological demands and decision latitude have little influence on the 1-year evolution of back-related functional limitations for one-time and recurrent back-pain problems. However, our results suggest that this association could be important for workers with persistent pain.
\end{abstract}

Key terms back pain, decision latitude, disability, psychological demands, psychosocial work environment, social support.

Back pain is one of the most common health problems and has a major impact on the quality of life of adults in industrialized countries (1-3). Although only a small proportion of those affected becomes disabled, in the long-term, this problem generates huge human and financial costs $(4,5)$.

The development of back pain and disability is influenced by multiple factors, such as psychological variables and physical work characteristics (5-7). If backpain symptoms can be precipitated by the physical demands of work, it seems plausible that back-related disability would be more the result of individual variables or work-related psychosocial factors than of the physical demands of work or clinical features $(7,8)$. In recent years, several investigators have reported that symptoms of back pain among workers are associated with the psychosocial characteristics of work $(1,9-14)$, although the mechanisms through which specific psychosocial work characteristics would affect back pain are still only speculative (15-17). However, most studies have focused on the impact of the psychosocial characteristics of the work environment on the occurrence of back pain, and little attention has been given to the association of these factors with the consequences of back pain. In consideration of the fact that the burden of back pain is determined mostly by the minority of cases that sustain severe consequences $(4,5)$, the examination of this relationship appears important.

1 Population Health Research Unit, Research Center of the Laval University Affiliated Hospital, Quebec City, Quebec, Canada.

2 Department of Rehabilitation, Faculty of Medicine, Laval University, Sainte-Foy, Quebec, Canada.

3 Local Community Health Care Center (CLSC) Haute-Ville-des-Rivières, Quebec City, Quebec, Canada.

Reprint requests to: Isabelle Leroux, Unité de recherche en santé des populations, Centre de recherche du CHA de Québec, Hôpital du St-Sacrement, 1050 chemin Ste-Foy, Québec (QUE) Canada, G1S 4L8. [E-mail: isabelle.leroux@uresp.ulaval.ca] 
There are some indications in the literature that high psychological demands, low decision latitude, and low social support at work may be risk factors for back-related disability. Recently, a retrospective cohort study of 433 workers' compensation claims for low-back pain found that high psychological job demand and low supervisory support were both associated with lower rates of return to work during all phases of a back-pain episode and that high job control was associated with higher rates of return to work during the subacute and chronic phases (18). A recent cross-sectional study conducted among Canadian workers from a wide range of occupations also found that high psychological demands and low social support at work are independently associated with more activity limitations due to musculoskeletal disorders, although these associations are only significant for women. Decision latitude has shown inconsistent relations with restricted activity (10).

Psychosocial job factors are often studied using Karasek's job strain model. This model postulates that workers exposed to high strain, a combination of high psychological demands and low decision latitude, are at higher risk of developing disease. Moreover, high social support at work may attenuate the negative effect of high job strain (19). Therefore, it could be hypothesized that workers in high strain jobs may have more back-related functional limitations and a modifying effect of social support at work could be expected. Since job dissatisfaction (20) and psychological distress (21) have been consistently associated with the functional consequences of back pain, one could argue that these factors could act as intervening factors in the association between psychosocial characteristics of work and back-related functional limitations.

If the limited scientific evidence on the role of psychosocial characteristics of the work environment in determining the consequences of back pain is considered, the aim of our prospective cohort study was to assess the associations between some psychosocial characteristics of work (psychological demands, decision latitude and social support) on one hand and back-related functional limitations 1 year later on the other. Secondary objectives were to determine if social support at work modified these associations and if psychological distress and job satisfaction could act as intervening factors.

\section{Participants and methods}

\section{Study design}

This study was based on analyses of the RAMS-Prognosis study data. This 2-year prospective study with repeated measurements aimed at describing the evolution of back-related disability among workers seeking medical consultation in primary care settings, identifying variables associated with the long-term occupational outcome of back pain, and building a prognostic tool that could be used in primary care settings to identify workers who need more specialized intervention. The current study is based on data collected at baseline and the 1-year follow-up.

\section{Study settings and selection of participants}

The participants were recruited in 1999-2000 in four large emergency rooms and three family medicine practices in the Quebec City area. All workers were considered eligible if they had sought consultation for nonspecific back pain (including the thoracic, lumbar, and lumbosacral areas) having affected their capacity to accomplish their regular work for at least 1 day, were aged 18-64 years, and were fluent in French. Eligible persons had to have had the same job for at least 3 months at the time of the baseline interview, and they had to have a job to which to return. This criterion was applied to ensure a minimum exposure time to the work environment. Workers suffering from specific pathologies, such as cancer, spinal infections, vertebral fractures, systemic disease, cauda equina syndrome, or referred pain were excluded. Pregnant women and subjects with major medical illnesses (eg, severe heart disease and psychiatric illness) that could affect their work status were also excluded. All the participants had to provide an informed consent. This study was approved by the ethics committees of all the institutions involved.

\section{Data collection}

Data were mainly collected in structured telephone interviews. The participants were contacted about 3 weeks after their medical visit and were asked to answer questions on their back-pain episodes, pain history, back-related functional limitations, psychosocial and physical work characteristics (frequency of trunk flexion, lateral bending, torsion, heavy lifting and whole-body vibration). Other questions were asked about individual factors that were considered to be potential confounders, such as symptoms of depression and somatization (22), stressful events in the past year (23), fear-avoidance beliefs about back pain (activity and work) (24), cigarette smoking, and sociodemographic and anthropometric variables. Some information, for example, medical diagnoses, was drawn from medical records.

Outcome measure. Back-related functional limitations were measured at baseline and 1 year later with a French translation of the Roland-Morris Disability Questionnaire that was validated by back-translation, according to the method proposed by Vallerand (25). 
Each item covered different aspects of daily life activities and asked the participants to answer, by yes or no, if the statement currently applied to them. This questionnaire has been widely and successfully administered on paper and over the phone (26). Many studies have found this instrument valid, reliable, and sensitive to clinically significant changes (26-28). The score of this scale ranged from 0 to 24, but was transformed to a scale of 0 to 100 in the analyses, higher scores corresponding to more important functional limitations.

Psychosocial factors at work. Psychological job demands (9 items, score range -6 to 21) and job decision latitude (9 items, score range 24 to 96 ) were measured at baseline with a French version of Karasek's Job Content Questionnaire (29) that has demonstrated good validity among white- and blue-collar workers from Quebec (30, 31). Psychological demands evaluate the quantity of work, the time constraints, and the conflicting demands of the job. Decision latitude evaluates the opportunities to make decisions, to be creative, and to use and develop one's abilities at work. High and low categories were determined by a cutoff point at the median of the distribution of the total score of each of these two variables in our study population. Workers were considered exposed to high psychological demands if their score was $\geq 9$ and to low decision latitude if their score was $\leq 70$. These values also correspond to the medians estimated for workers of the Province of Quebec in 1998 (32).

According to Karasek's job strain model (19), a new variable has been created to classify workers into four exposed groups: (i) the more exposed group, "high strain", defined by the combination of high psychological demands and low decision latitude, (ii) the "active" group (high decision latitude and high psychological demands), (iii) the "passive" group (low decision latitude and low psychological demands), and (iv) the reference group (high decision latitude and low psychological demands).

Social support at work was assessed at baseline with the modified Work APGAR (adaptation, partnership, growth, affection and resolve) scale (1). This seven-item scale (score range 1-3) has been used in other studies on back pain to examine perceptions of support at the workplace and job enjoyment $(1,20,33,34)$. In our study, the scores were dichotomized using the median of the total sample. Workers who obtained a score of $\geq 1.9$ were considered exposed to low social support at work.

Possible intervening factors. Psychological distress during the last month was measured with 17 items drawn from subscales of the Symptoms Checklist-90 (SCL-90) (22). Job satisfaction was assessed with one question: "In a general way, would you say that your work satisfies you entirely, moderately, a little or not at all?" The answers were grouped into the following three catego- ries in the analyses: (i) "entirely", (ii) "moderately", and (iii) "little" or "not at all".

\section{Statistical analyses}

All the analyses were performed using the SAS computer program, version 8.1 (35). Separate analyses were carried out for the men and women to allow a comparison of our results with those of other studies. Bivariate analyses were conducted with the Student's t and chisquare tests (36). Since the joint distribution of the Roland-Morris scores at baseline and at follow-up was linear, analyses of covariance were conducted to compare means of functional limitations at 1 year according to the different dimensions of the job strain model (37), with adjustment for the baseline Roland-Morris score. Therefore the Roland-Morris score at the 1-year followup was standardized for the score at baseline. We conducted two sets of analyses, one that considered psychological demands and decision latitude as two independent factors and another that included the variable classifying jobs as high strain, active, passive, or low strain in the statistical models. Since there was no interaction between psychological demands and decision latitude (women $\mathrm{P}=0.217$, men $\mathrm{P}=0.634$ ), the two dimensions were finally considered independently. The potentially modifying effect of social support at work was assessed by stratification. Subsequent analyses were also done by considering separately the different types of back pain (one-time, recurrent or persistent) because a modifying effect of this variable was suspected.

Multiple regression was used to adjust for confounding factors (37). If the coefficient of regression of the independent variable in a crude model changed by one unit or more after the inclusion of a variable, this variable was considered a confounder and was retained for the multivariate analyses. A criterion of one unit was selected because it represented $10 \%$ of 10 points, the smallest clinically significant change (38) on the Roland-Morris score. Multivariate models that included all the confounders were then built. Only variables that met our criteria for confounding were kept in the final models, except age, which was forced. The adjusted means of the 1-year Roland-Morris score and the $95 \%$ confidence intervals $(95 \% \mathrm{CI})$ were calculated for each model.

To investigate whether psychological distress and job satisfaction were intervening factors in the relationship between psychosocial work characteristics and back-related functional limitations 1 year later, analyses were performed with and without adjustment for these variables.

\section{Description of participants}

A total of 1007 persons, $68 \%$ of all those eligible, agreed to participate to this study and completed the telephone 
interview at baseline. Among persons who were still eligible (were not deceased) 1 year later, 888 subjects (88.2\%) completed the 1-year follow-up interview. On a post hoc verification, 39 participants were excluded because they had not been at the same job for at least 3 months at the baseline interview. Finally, the data of 483 men and 366 women (total=849) were used in the analyses. Table 1 presents selected baseline characteristics of the participants. Most of the participants were male and married or living as married. The highest level of formal education completed was most often primary or secondary school. Most of the participants worked fulltime. More than half of the men and women reported high psychological demands at work, and low decision latitude was also frequent. The participants reported mainly a recurrent or persistent back-pain problem.

The participants were more often of female gender than the eligible persons who did not participate $(\mathrm{P}$-value $=0.02)$. However, there were no statistical differences according to age. Furthermore, some differences were noted between the participants who

Table 1. Selected baseline characteristics of the participants.

\begin{tabular}{|c|c|c|c|c|c|c|c|c|}
\hline \multirow[t]{2}{*}{ Variables } & \multicolumn{4}{|c|}{ Men $(\mathrm{N}=483)$} & \multicolumn{4}{|c|}{ Women $(\mathrm{N}=366)$} \\
\hline & $\begin{array}{l}\text { Miss- } \\
\text { ing } \\
\text { values }\end{array}$ & & SD & $\%$ & $\begin{array}{l}\text { Miss- } \\
\text { ing } \\
\text { values }\end{array}$ & - Mean & SD & $\%$ \\
\hline Age (years) & - & 39.4 & 10.3 & & - & 38.41 & 10.9 & . \\
\hline Marital status & 1 & & & & 1 & & & \\
\hline $\begin{array}{l}\text { Married or living as married } \\
\text { Living alone }\end{array}$ & & $\cdot$ & $\cdot$ & $\begin{array}{l}73.0 \\
27.0\end{array}$ & & . & $\dot{ }$ & $\begin{array}{l}66.6 \\
33.4\end{array}$ \\
\hline Education & 3 & & & & - & & & \\
\hline $\begin{array}{l}\text { Primary or secondary } \\
\text { College } \\
\text { University }\end{array}$ & & $\dot{.}$ & $\begin{array}{l}\cdot \\
\cdot \\
\cdot\end{array}$ & $\begin{array}{l}58.1 \\
27.5 \\
14.4\end{array}$ & & $\dot{r}$ & & $\begin{array}{l}41.3 \\
36.1 \\
22.7\end{array}$ \\
\hline Work schedule & - & & & & - & & & \\
\hline $\begin{array}{l}\text { Full-time } \\
\text { Part-time }\end{array}$ & & $\dot{r}$ & $\cdot$ & $\begin{array}{l}88.0 \\
12.0\end{array}$ & & . & $\dot{ }$ & $\begin{array}{l}70.8 \\
29.2\end{array}$ \\
\hline $\begin{array}{l}\text { Duration of work in same job } \\
\text { (years) }\end{array}$ & b - & 8.4 & 8.3 & 3. & - & 7.2 & 8.1 & . \\
\hline $\begin{array}{l}\text { Stressful life events a } \\
\text { in past } 12 \text { months }\end{array}$ & 1 & & & & - & & & \\
\hline $\begin{array}{l}\text { Yes } \\
\text { No }\end{array}$ & & $\dot{.}$ & $\cdot$ & $\begin{array}{l}53.3 \\
46.7\end{array}$ & & $\dot{.}$ & $\dot{ }$ & $\begin{array}{l}62.3 \\
37.7\end{array}$ \\
\hline Baseline Roland-Morris score & re 1 & 45.8 & 28.9 & . & 1 & 48.92 & 27.0 & . \\
\hline Self-reported type of episode & e 3 & & & & - & & & \\
\hline $\begin{array}{l}\text { One-time } \\
\text { Recurrent } \\
\text { Persistent }\end{array}$ & & $\dot{.}$ & $\cdot$ & $\begin{array}{l}20.2 \\
48.5 \\
31.3\end{array}$ & & $\dot{.}$ & $\dot{.}$ & $\begin{array}{l}25.7 \\
46.7 \\
27.6\end{array}$ \\
\hline Psychological demands & 3 & & & & - & & & \\
\hline $\begin{array}{l}\text { High } \\
\text { Low }\end{array}$ & & . & $\cdot$ & $\begin{array}{l}53.3 \\
46.7\end{array}$ & & . & . & $\begin{array}{l}59.0 \\
41.0\end{array}$ \\
\hline Decision latitude & 1 & & & & - & & & \\
\hline $\begin{array}{l}\text { High } \\
\text { Low }\end{array}$ & & $\dot{r}$ & $\cdot$ & $\begin{array}{l}47.9 \\
52.1\end{array}$ & & . & . & $\begin{array}{l}41.8 \\
58.2\end{array}$ \\
\hline
\end{tabular}

a At least one of the following: unsatisfactory job change, split or divorce, important financial problems, subject or significant other severely ill, death of spouse or significant other. completed the 1-year follow-up interview and those who did not. Participants of both genders lost to follow-up were less educated and more often cigarette smokers, and a higher proportion reported at least one stressful event in the past year at baseline. In addition, women lost to follow-up were more often exposed simultaneously $(\mathrm{P}$-value $=0.07)$ to low social support at work and low decision latitude ( $\mathrm{N}=16-59 \%)$, comparatively to women who completed the 1-year interview ( $\mathrm{N}=119-$ $35 \%)$. They also had a higher baseline Roland-Morris score (mean $59.0 \%$, SD 27.6) than the women who completed the follow-up (mean 48.9\%, SD 27.0, P-value $=0.06)$ (data not shown).

\section{Results}

In the bivariate analyses, several of the variables considered were statistically associated with the outcome (table 2). The 1-year mean Roland-Morris scores differed statistically among both the women and the men by self-reported type of back-pain episode, symptoms of somatization and depression, self-reported health status, job insecurity, and psychological job demands measured at baseline. The worst intensity of back pain in the 6 months preceding the 1-year follow-up interview was also strongly associated with the 1-year Roland-Morris score. A statistically significant association was observed with physical workload only for the men. No statistically significant associations $(\alpha>0.05)$ were found with job decision latitude, social support at work, job satisfaction, age, or education in the bivariate analyses.

Since a modifying effect of social support at work on the association between decision latitude and backrelated functional limitations was identified for both the women $(\mathrm{P}=0.056)$ and the men $(\mathrm{P}=0.096)$, analyses were stratified on decision latitude according to social support at work for both genders. However, the analyses on the association between psychological demands and functional limitations were stratified for social support at work only for the men $(\mathrm{P}=0.051)$ because no effect modification was found for the women $(\mathrm{P}=0.809)$. After adjustment for confounders, a statistically significant association was observed between job decision latitude and back-related functional limitations among the women. Those who reported high social support at work and high decision latitude had higher 1-year RolandMorris scores (mean 30.7, SD 1.8) than the women who reported low social support at work and high decision latitude (mean 21.8, SD 3.1). These scores were adjusted for age, symptoms of somatization, and the worst pain intensity of the past 6 months. Psychological job demands was also found to be statistically significant 
Table 2. Bivariate associations of selected variables with the 1-year Roland-Morris score, adjusted for the baseline Roland-Morris score and presented by gender.

\begin{tabular}{|c|c|c|c|c|c|c|c|c|}
\hline \multirow[t]{3}{*}{ Variables } & \multicolumn{4}{|c|}{ Men $(\mathrm{N}=482)$} & \multicolumn{4}{|c|}{ Women $(N=364)$} \\
\hline & \multirow[t]{2}{*}{$\mathrm{N}$} & \multicolumn{2}{|c|}{ One-year follow-up a score } & \multirow{2}{*}{$\begin{array}{l}\text { P-value }{ }^{b} \\
(\alpha=0.05)\end{array}$} & \multirow[t]{2}{*}{$\mathrm{N}$} & \multicolumn{2}{|c|}{ One-year follow-up a score } & \multirow{2}{*}{$\begin{array}{l}\text { P-value }{ }^{b} \\
(\alpha=0.05)\end{array}$} \\
\hline & & Mean & $95 \% \mathrm{Cl}$ & & & Mean & $95 \% \mathrm{Cl}$ & \\
\hline \multicolumn{2}{|c|}{ Self-reported type of episode } & & & $<0.001$ & & & & $<0.001$ \\
\hline One-time & 97 & 12.9 & $8.54-17.3$ & & 94 & 18.6 & $14.2-23.0$ & \\
\hline Recurrent & 232 & 20.6 & $17.7-23.4$ & & 170 & 26.0 & $22.7-29.3$ & \\
\hline Persistent & 150 & 30.7 & $27.1-34.4$ & & 100 & 34.4 & $30.0-38.8$ & \\
\hline \multicolumn{2}{|l|}{ Somatization score } & & & $<0.001$ & & & & $<0.001$ \\
\hline $0-0.43$ & 172 & 15.8 & $12.4-19.1$ & & 98 & 20.8 & $16.3-25.2$ & \\
\hline $0.44-0.86$ & 106 & 19.4 & $15.2-23.5$ & & 65 & 15.2 & $10.0-20.4$ & \\
\hline $0.87-1.57$ & 132 & 23.8 & $20.0-27.5$ & & 95 & 29.5 & $25.2-33.8$ & \\
\hline $1.58-4.00$ & 72 & 39.1 & $33.8-41.3$ & & 106 & 35.8 & $31.5-40.0$ & \\
\hline \multicolumn{2}{|l|}{ Depression score } & & & $<0.001$ & & & & 0.049 \\
\hline $0-0.70$ & 172 & 16.3 & $12.9-19.8$ & & 70 & 23.4 & $17.9-28.9$ & \\
\hline $0.71-1.30$ & 103 & 18.3 & $14.1-22.5$ & & 86 & 21.9 & $17.2-26.7$ & \\
\hline $1.31-2.10$ & 131 & 25.2 & $21.4-29.0$ & & 105 & 27.5 & $23.2-31.8$ & \\
\hline $2.11-4.00$ & 76 & 35.8 & $30.8-40.8$ & & 105 & 31.1 & $26.6-35.6$ & \\
\hline \multicolumn{3}{|c|}{ Self-reported health status } & & $<0.001$ & & & & 0.048 \\
\hline Excellent & 103 & 19.2 & $14.9-23.6$ & & 61 & 22.4 & $16.7-28.0$ & \\
\hline Very good & 145 & 19.1 & $15.4-22.7$ & & 125 & 23.9 & $20.0-27.8$ & \\
\hline Good & 160 & 22.0 & $18.5-25.4$ & & 108 & 28.3 & $24.1-32.5$ & \\
\hline Fair or poor & 74 & 33.2 & $28.0-38.4$ & & 70 & 31.6 & $26.3-36.9$ & \\
\hline \multicolumn{4}{|c|}{ Likelihood of losing job within 2 years } & $<0.001$ & & & & 0.019 \\
\hline Very likely & 42 & 31.0 & $24.2-37.7$ & & 38 & 33.8 & $26.8-40.8$ & \\
\hline Likely & 86 & 28.5 & $23.7-33.2$ & & 67 & 26.6 & $21.3-31.9$ & \\
\hline Unlikely & 103 & 17.4 & $13.1-21.7$ & & 83 & 20.8 & $16.1-25.5$ & \\
\hline Very unlikely & 237 & 20.2 & $17.3-23.0$ & & 165 & 27.5 & $24.2-30.9$ & \\
\hline \multicolumn{4}{|c|}{ Psychological job demands } & 0.001 & & & & 0.014 \\
\hline High & 255 & 25.6 & $22.8-28.4$ & & 214 & 28.8 & $25.8-31.8$ & \\
\hline Low & 224 & 18.3 & $15.4-21.3$ & & 150 & 22.9 & $19.3-26.5$ & \\
\hline \multicolumn{4}{|c|}{ Worst intensity of back pain in past 6 months ${ }^{c}$} & $<0.001$ & & & & $<0.001$ \\
\hline $0-4$ & 169 & 7.00 & $4.10-9.91$ & & 101 & 10.5 & $6.52-14.6$ & \\
\hline $5-7$ & 148 & 22.6 & $19.5-25.6$ & & 103 & 24.1 & $20.3-27.9$ & \\
\hline $8-10$ & 165 & 37.6 & $34.6-40.5$ & & 160 & 37.9 & $34.8-41.0$ & \\
\hline \multicolumn{4}{|c|}{ Physical workload (level of physical effort $x$ lifting heavy load) } & 0.002 & & & & 0.878 \\
\hline $1^{\text {st }}$ quartile & 110 & 20.1 & $15.8-24.3$ & & 93 & 27.6 & $23.0-32.1$ & \\
\hline $2^{\text {nd }}$ quartile & 121 & 19.3 & $15.3-23.3$ & & 104 & 25.9 & $21.6-30.3$ & \\
\hline $3^{\text {rd }}$ quartile & 144 & 20.8 & $17.1-24.5$ & & 105 & 25.2 & $20.9-29.5$ & \\
\hline $4^{\text {th }}$ quartile & 104 & 29.8 & $25.5-34.1$ & & 60 & 27.2 & $21.5-32.9$ & \\
\hline
\end{tabular}

a Score range: $0-100$.

b P-value comparing means at the one-year follow-up according to categories of each variable presented in the table.

${ }^{c}$ Eleven-point numerical rating scale.

for the women, but the difference between the means was very small (table 3 ).

Since job satisfaction and symptoms of depression and somatization had no or only marginal confounding effects in the multivariate models, these variables were not considered to be intervening factors (data not shown).

The results of the analyses stratified according to the type of back pain suggested a modifying effect of this variable, especially when the combination of psychological demands and decision latitude (job strain) was studied. For the participants with persistent back pain, those who reported low psychological demands and high decision latitude (reference category) had lower levels of back-related functional limitations than those in the other three categories of the job strain model (table 4). The largest difference, although not statistically significant, was 16.4 for the men and 19.7 for the women.

\section{Discussion}

The results of this study indicate that psychological demands and decision latitude at work have little influence on the evolution of back-related functional limitations 
Table 3. Association of psychosocial job factors with the 1-year back-related functional limitations a - results of the crude and multivariate analyses by gender.

\begin{tabular}{|c|c|c|c|c|c|c|c|c|}
\hline \multirow[t]{2}{*}{ Gender } & \multicolumn{4}{|c|}{ Crude values } & \multicolumn{4}{|c|}{ Adjusted values } \\
\hline & $\mathrm{N}$ & Mean & $95 \% \mathrm{Cl}$ & $\begin{array}{l}\text { P-value } \\
(\alpha=0.05)\end{array}$ & $\mathrm{N}$ & Mean & $95 \% \mathrm{Cl}$ & $\begin{array}{l}\text { P-value } \\
(\alpha=0.05)\end{array}$ \\
\hline \multicolumn{9}{|l|}{ Men } \\
\hline \multirow{2}{*}{\multicolumn{3}{|c|}{$\begin{array}{l}\text { Psychological demands } \times \text { social support at work } \\
\text { High demands }\end{array}$}} & & \multirow[t]{2}{*}{0.001} & & & & \multirow[t]{2}{*}{0.186} \\
\hline & & & & & & & & \\
\hline Low social support & 156 & 23.7 & $20.2-27.3$ & & 155 & $22.2^{b}$ & $19.2-25.2$ & \\
\hline High social support & 96 & 27.9 & $23.3-32.4$ & & 96 & 24.8 & $21.0-28.6$ & \\
\hline \multicolumn{9}{|l|}{ Low demands } \\
\hline Low social support & 100 & 20.1 & $15.7-24.6$ & & 99 & 22.0 & $18.3-25.7$ & \\
\hline High social support & 106 & 15.9 & $11.5-20.2$ & & 105 & 19.0 & $15.3-22.6$ & \\
\hline \multicolumn{3}{|c|}{ Decision latitude $\times$ social support at work } & & 0.382 & & & & 0.235 \\
\hline \multicolumn{9}{|l|}{ Low latitude } \\
\hline Low social support & 155 & 23.4 & $19.8-27.1$ & & 155 & $23.5^{c}$ & $20.5-26.5$ & \\
\hline High social support & 89 & 18.9 & $14.1-23.7$ & & 89 & 19.1 & $15.1-23.1$ & \\
\hline \multicolumn{9}{|l|}{ High latitude } \\
\hline Low social support & 103 & 21.0 & $16.5-25.4$ & & 101 & 20.6 & $16.8-24.3$ & \\
\hline High social support & 113 & 23.7 & $19.4-27.9$ & & 112 & 23.5 & $19.9-27.1$ & \\
\hline \multicolumn{9}{|l|}{ Women } \\
\hline \multicolumn{3}{|l|}{ Psychological demands } & & \multirow[t]{3}{*}{0.014} & & & & \multirow[t]{3}{*}{0.048} \\
\hline High & 214 & 28.8 & $25.8-31.8$ & & 214 & $28.1^{d}$ & $25.5-30.8$ & \\
\hline Low & 150 & 22.9 & $19.3-26.5$ & & 150 & 23.9 & $20.8-27.1$ & \\
\hline \multicolumn{3}{|c|}{ Decision latitude $\times$ social support at work } & & \multirow[t]{2}{*}{0.210} & & & & \multirow[t]{2}{*}{0.025} \\
\hline \multicolumn{7}{|l|}{ Low latitude } & & \\
\hline Low social support & 118 & 27.1 & $23.0-31.1$ & & 118 & $25.5^{\mathrm{e}}$ & $22.2-28.8$ & \\
\hline High social support & 83 & 22.9 & $18.1-27.7$ & & 83 & 23.9 & $19.9-27.9$ & \\
\hline \multicolumn{9}{|l|}{ High latitude } \\
\hline Low social support & 36 & 23.1 & $15.8-30.3$ & & 36 & 21.8 & $15.7-27.9$ & \\
\hline High social support & 102 & 29.2 & $24.9-33.5$ & & 102 & 30.7 & $27.1-34.3$ & \\
\hline
\end{tabular}

a All the means have been adjusted for the baseline Roland-Morris scores.

${ }^{b}$ Adjusted for age, symptoms of depression, worst intensity of back pain in the past 6 months, and physical workload.

${ }^{c}$ Adjusted for age, education, and worst intensity of back pain in the past 6 months.

d Adjusted for age and worst intensity of back pain in the past 6 months.

e Adusted for age, symptoms of somatization, and worst intensity of back pain in the past 6 months.

Table 4. Crude and adjusted means and 95\% confidence intervals $(95 \% \mathrm{Cl})$ for the association between job strain and 1-year backrelated functional limitations ${ }^{\text {a }}$ among the participants with persistent back pain.

\begin{tabular}{|c|c|c|c|c|c|c|c|c|}
\hline \multirow{3}{*}{$\begin{array}{l}\text { Psychological demands } \times \\
\text { decision latitude }\end{array}$} & \multicolumn{4}{|c|}{ Men } & \multicolumn{4}{|c|}{ Women } \\
\hline & \multicolumn{2}{|c|}{ Crude values } & \multicolumn{2}{|c|}{ Adjusted values ${ }^{b}$} & \multicolumn{2}{|c|}{ Crude values } & \multicolumn{2}{|c|}{ Adjusted valuesc } \\
\hline & Mean & $95 \% \mathrm{Cl}$ & Mean & $95 \% \mathrm{Cl}$ & Mean & $95 \% \mathrm{Cl}$ & Mean & $95 \% \mathrm{Cl}$ \\
\hline High demands, low latitude & 41.0 & $32.5-49.6$ & 39.4 & $30.4-48.4$ & 40.6 & $33.2-48.1$ & 38.7 & $30.8-46.5$ \\
\hline Low demands, low latitude & 32.5 & $23.0-42.1$ & 37.4 & $27.0-47.7$ & 45.8 & $34.9-56.7$ & 43.4 & $30.6-56.2$ \\
\hline High demands, high latitude & 36.8 & $29.2-44.5$ & 34.7 & $26.9-42.5$ & 42.5 & $34.6-50.3$ & 39.8 & $30.8-48.8$ \\
\hline Low demands, high latitude & 27.0 & $16.6-37.4$ & 23.0 & $11.6-34.4$ & 25.7 & $14.2-37.2$ & 23.7 & $10.1-37.3$ \\
\hline
\end{tabular}

a All the means have been adusted for the baseline Roland-Morris scores.

${ }^{\mathrm{b}}$ Adusted for age, social support at work, physical job demands, and smoking habits.

${ }^{c}$ Adjusted for age, social support at work, and physical job demands.

when people are considered irrespective of their type of back pain. Although a statistically significant association was found for the women, between decision latitude and functional limitations according to the level of social support at work, the difference in the observed means (9\%) falls below the clinical significance threshold. Indeed, it is recommended that a change of 2 to 3 points on the
Roland-Morris questionnaire on its 0 to 24 scale (about $10 \%$ ) should be considered the minimum clinically important change (38).

The results of the multivariate analyses with and without adjustment for job satisfaction, symptoms of depression, and symptoms of somatization do not allow us to conclude that these variables play an intervening 
role in the association between psychological demands or decision latitude and back-related functional limitations.

While Karasek's model postulates an effect modification on a multiplicative scale between decision latitude and psychological demands, we did not identify this phenomenon in our study, except when analyses were stratified according to the type of back pain. To our knowledge, only one study has assessed effect modification between psychological job demands and decision latitude in relation to functional restrictions due to musculoskeletal disorders, and the results were negative (10).

Our results are difficult to compare with those obtained in other studies due to differences in the analyses performed and the outcomes studied. Almost all previous studies have focused on the frequency of back pain instead of on the frequency of functional limitations. Only one prospective study has investigated the possible intervening role of psychosocial variables in the association between psychosocial work factors and the risk of low back pain (39). This study reported that job satisfaction, emotional exhaustion, and sleep difficulties were not intermediate in the relationship between conflicting demands, supervisors' and co-workers' support, and low-back pain. However, an intermediate role of the general opinion about the job and emotional exhaustion was considered possible in the association between high quantitative job demands and low-back pain.

In this prospective study, we used standardized questionnaires to measure psychosocial factors at work and functional limitations. We examined the effects of several potential confounders. Since we controlled for the baseline level of functional limitations and adjusted for the best known confounders in the analyses, we are confident that we identified a valid estimate of the contribution of the psychosocial job factors examined on the evolution of back-related functional limitations.

Because the eligible persons who agreed to participate in the study were more often of female gender than the eligible persons who did not participate at baseline, our results could have been affected by a selection bias, given that the association between psychosocial factors at work and back-related functional limitations differ between the genders. Moreover, the participants who did not complete the study differed as to several characteristics when compared with the other participants. It is possible that the women lost to follow-up were at higher risk of severe functional limitations 1 year later. Although the effect of such a selection bias was reduced by the small number of participants $(\mathrm{N}=16)$, it is a possibility that cannot be excluded, and its overall possible effect on our results is difficult to estimate.

The impact of social support at work among the women differed considerably according to the level of decision latitude (high or low). We found, unexpectedly, that, among the women who reported high decision latitude, those who perceived high social support at work had more functional limitations than those who perceived low social support. Conversely, among the women who reported low decision latitude, high social support tended to reduce the level of functional limitations. According to Karasek's model, high decision latitude and high social support at work should reduce the negative effect of psychological demands on the health of workers (19). We cross-checked our analyses with various strategies. All of them converged to the same conclusions. The most probable explanation for this finding lies in a likely selection bias linked with the fact that prevalent cases of back pain (some of them of long duration) were included in this study. This bias would occur if women with recurrent and persistent functional limitations were more likely to stay in the labor market when they had high job decision latitude and high social support at work.

Comparisons of the characteristics of the participants at baseline according to the type of back pain produced no significant difference for age, decision latitude, psychological demands, social support at work, physical job demands, income, and job seniority among both the men and the women. However, men with persistent back pain had a lower level of education than those with one-time or recurrent back pain.

The results of our analyses on the type of back pain suggest that psychosocial factors at work, especially job strain, may influence recovery from back-related functional limitations, at least, among people with persistent back pain. Since three levels of interaction were considered, some cells had small numbers of participants that limited these analyses and the effective statistical power. It is plausible to believe that people with persistent back pain may be more vulnerable to the psychosocial environment of work than workers with a onetime episode.

The longitudinal design of this study made it possible to evaluate the impact of psychosocial factors at work on functional limitations 1 year after a medical consultation for a nonspecific back-pain problem. However, the results may have been influenced by the fact that the baseline interview occurred about 3 weeks after the index visit. Thus it is likely that the baseline Roland-Morris scores have been affected by the interval of time required before the baseline interview could be conducted. The participants who completed the baseline interview later had a better opportunity to recover from back pain, and therefore smaller differences could have resulted between the baseline and 1-year Roland-Morris scores. Such nondifferential misclassification of the outcome variable is likely to have resulted in an underestimation of the association of the psychosocial job factors with 1-year back-related functional limitations 
by incomplete adjustment for the baseline Roland-Morris score in the analyses.

The evaluation of the characteristics of the work environment was based on self-report after the back-pain onset. It is possible that workers with more back-related functional limitations reported higher constraints in their work environment. In such a case, differential misclassification of the participants' exposure could have resulted in over- or underestimation of the associations. Another potential information bias lies in the fact that some of the participants (26 women and 26 men) had not returned to work by the time of the 1-year followup, but they were nevertheless considered exposed to the same level of psychosocial environment. This situation could also have contributed to underestimate the associations under study.

As workers who seek medical consultation in primary care settings for back pain could have different characteristics than workers who do not consult, the interpretation of the results of our study must be limited to a similar population.

In conclusion, the results of our study indicate that, overall, psychological demands and decision latitude at work have little influence on the 1-year evolution of back-related functional limitations among workers who seek medical consultation in primary care settings. They suggest, however, a possible deleterious effect of job strain on back-related functional limitations among workers with persistent back pain. Future studies on psychosocial job factors and back-related functional limitation should take into account the potential modifying effect of the type of back pain.

\section{Acknowledgments}

This study was supported by a grant from the Quebec Institute for Occupational Safety and Health (IRSSTInstitut Robert-Sauvé de recherche en santé et sécurité au travail).

This paper reports part of the master's thesis in epidemiology of I Leroux, conducted under the supervision of CE Dionne and R Bourbonnais. CE Dionne and R Bourbonnais hold research scholarships from the Quebec Health Research Funds (FRSQ).

\section{References}

1. Bigos SJ, Battie MC, Spengler DM, Fisher LD, Fordyce WE, Hansson T, et al. A longitudinal, prospective study of industrial back injury reporting. Clin Orthop 1992;279:21-34.

2. Cassidy JD, Carroll LJ, Côté P. The Saskatchewan health and back pain survey: the prevalence of low back pain and related disability in Saskatchewan adults. Spine 1998; 23(17):1860-6.

3. Hart LG, Deyo RA, Cherkin DC. Physician office visits for low back pain: frequency, clinical evaluation, and treatment patterns from a U.S. national survey. Spine 1995;20(1):11-9.

4. Abenhaim L, Suissa S. Importance and economic burden of occupational back pain: a study of 2,500 cases representative of Quebec. J Occup Med 1987;29(8):670-4.

5. Frank JW, Kerr MS, Brooker AS, DeMaio SE, Maetzel A, Shannon HS, et al. Disability resulting from occupational low back pain, part I: what do we know about primary prevention? a review of the scientific evidence on prevention before disability begins. Spine 1996;21(24):2908-17.

6. Kerr MS, Frank JW, Shannon HS, Norman RW, Wells RP, Neumann WP, et al. Biomechanical and psychosocial risk factors for low back pain at work. Am J Public Health 2001;91(7):1069-75.

7. Waddell G. The back pain revolution. Edinburgh: Churchill Livingstone; 1998.

8. Waddell G, Burton AK. Occupational health guidelines for the management of low back pain at work: evidence review. Occup Med 2001;51(2):124-35.

9. Ahlberg-Hultén GK, Theorell T, Sigala F. Social support, job strain and musculoskeletal pain among female health care personnel. Scand J Work Environ Health 1995;21(6):435-9.

10. Cole DC, Ibrahim SA, Shannon HS, Scott F, Eyles J. Work correlates of back problems and activity restriction due to musculoskeletal disorders in the Canadian national population health survey (NPHS) 1994-5 data. Occup Environ Med 2001;58(11):728-34.

11. Leino PI, Hänninen V. Psychosocial factors at work in relation to back and limb disorders. Scand J Work Environ Health 1995;21(2):134-42.

12. Torp S, Riise T, Moen BE. The impact of psychosocial work factors on musculoskeletal pain: a prospective study. J Occup Environ Med 2001;43(2):120-6.

13. Houtman ILD, Bongers PM, Smulders PGW, Kompier MAJ. Psychosocial stressors at work and musculoskeletal problems. Scand J Work Environ Health 1994;20(2):139-45.

14. Wahlstedt KG, Björkstén MG, Edling C. Factors at work and musculoskeletal symptoms among postal workers. Int J Behav Med 2001;8(3):181-93.

15. Davis KG, Heaney CA. The relationship between psychosocial work characteristics and low back pain: underlying methodological issues. Clin Biomechanics 2000;15(6):389-406.

16. Hoogendoorn WE, van Poppel MN, Bongers PM, Koes BW, Bouter LM. Systematic review of psychosocial factors at work and private life as risk factors for back pain. Spine 2000;25(16):2114-25.

17. Linton SJ. Occupational psychological factors increase the risk for back pain: a systematic review. J Occup Rehabil 2001;11(1):53-66.

18. Krause N, Dasinger LK, Deegan LJ, Rudolph L, Brand RJ. Psychosocial job factors and return-to-work after compensated low back injury: a disability phase-specific analysis. Am J Ind Med 2001;40(4):374-92.

19. Karasek R, Theorell T. Healthy work: stress, productivity, and the reconstruction of working life. New York (NY): Basic Books Inc; 1990.

20. Williams RA, Pruitt SD, Doctor JN, Epping-Jordan JE, Wahlgren DR, Grant I, et al. The contribution of job satisfaction to the transition from acute to chronic low back pain. Arch Phys Med Rehabil 1998;79(4):366-74. 
21. Dionne CE, Koepsell TD, Von Korff M, Deyo RA, Barlow WE, Checkoway H. Predicting long-term functional limitations among back pain patients in primary care settings. J Clin Epidemiol 1997;50(1):31-43.

22. Derogatis LR. Symptoms checklist-90: administration, scoring and procedures manual for the revised version. Baltimore (MA): Clinical Psychometric Research; 1977.

23. Statistics Canada. National population health survey: large diffusion data guide. Ottawa: Statistics Canada; 1994:27-9.

24. Waddell G, Newton M, Henderson I, Somerville D, Main CJ. A fear-avoidance beliefs questionnaire (FABQ) and the role of fear-avoidance beliefs in chronic low back pain and disability. Pain 1993;52(2):157-68.

25. Vallerand RJ. Vers une méthode de validation trans-culturelle des questionnaires psychologiques: implications pour la recherche en langue française [A transcultural validation method for psychologic questionnaires : implications for research in French]. Can Psychol 1989;30:662.

26. Roland M, Fairbank J. The Roland-Morris disability questionnaire and the Oswestry disability questionnaire. Spine 2000;25(24):3115-24.

27. Beurskens AJ, de Vet HC, Koke AJ, van der Heijden GJ, Knipschild PG. Measuring the functional status of patients with low back pain: assessment of the quality of four diseasespecific questionnaires. Spine 1995;20(9):1017-28.

28. Jensen MP, Strom SE, Turner JA, Romano JM. Validity of the sickness impact profile Roland scale as a measure of dysfunction in chronic pain patients. Pain 1992;50(2):15762 .

29. Karasek R, Brisson C, Kawakami N, Houtman I, Bongers P, Amick B. The job content questionnaire (JCQ): an instrument for internationally comparative assessments of psychosocial job characteristics. J Occup Health Psychol 1998; $3(4): 322-55$.

30. Larocque B, Brisson C, Blanchette C. Cohérence interne, validité factorielle et validité discriminante de la traduction française des échelles de demande psychologique et de latitude décisionnelle du "Job Content Questionnaire" de Kara- sek [Internal consistency, factorial validity and discriminant validity of the French version of the psychological demands and decision latitude scales of the Karasek "Job Content Questionnaire"]. Rev Épidemiol Santé Publique 1998;46(5):371-81.

31. Brisson C, Blanchette C, Guimont C, Dion G, Moisan J, Vézina M, et al. Reliability and validity of the French version of the 18-item Karasek job content questionnaire. Work Stress 1998;12(4):322-36.

32. Daveluy C, Pica L, Audet N, Countemanche R, Lapointe, et al. Enquête sociale et de santé 1998 [Quebec health survey 1998]. Québec: Institut de la statistique du Québec; 2000. Report No.: 2e édition.

33. Friedrich M, Cermak T, Heiller I. Spinal troubles in sewage workers: epidemiological data and work disability due to low back pain. Int Arch Occup Environ Health 2000;73(4):24554.

34. Reigo T, Tropp H, Timpka T. Absence of back disorders in adults and work-related predictive factors in a 5-year perspective. Eur Spine J 2001;10(3):215-20.

35. SAS Institute Inc. The SAS System for Sun OS. Cary (NC): SAS Institute Inc; 2000.

36. Altman DG. Practical statistics for medical research. 1st ed. London: Chapman and Hall; 1991.

37. Kleinbaum DG, Kupper LL, Muller KE. Applied regression analysis and other multivariable methods. 2nd ed. Boston (NY): PWS-KENT Publishing Company; 1988.

38. Bombardier C, Hayden J, Beaton DE. Minimal clinically important difference: low back pain: outcome measures. J Rheumatol 2001;28(2):431-8.

39. Hoogendoorn WE, Bongers PM, de Vet HCW, Houtman ILD, Ariëns GAM, van Mechelen W, et al. Psychosocial work characteristics and psychological strain in relation to low-back pain. Scand J Work Environ Health 2001; 27(4):258-67.

Received for publication: 31 January 2003 